\title{
The energetic efficiency of metabolism
}

\section{By A. J. F. Webster, Department of Animal Husbandry, University of Bristol, Langford House, Langford, Bristol BS $18{ }_{7} D U$}

The efficiency with which an animal can utilize the metabolizable energy (ME) contained in the food it eats is determined by the amount of heat $(\mathrm{H})$ it produces in metabolism. This paper is devoted to an analysis of the factors which affect $\mathrm{H}$ in animals. The topic is of perennial interest to students of both animal and human nutrition concerned respectively with the efficient use of animal feedstuffs by livestock and with problems experienced by man in maintaining energy balance through adult life.

There are three ways by which one can approach the analysis of metabolic heat production. (I) Analysis by external inputs. Analysis of $\mathrm{H}$ according to measurable variables in the whole animal and its environment, namely size of animal, quantity and quality of food intake, behaviour and activity and the thermal environment. (2) Analysis by internal inputs. Analysis of $\mathrm{H}$ according to substrate kinetics and the enthalpy changes incurred thereby. (3) Analysis by internal output. Analysis according to the amount of work done by different organs and tissues in different circumstances.

These forms of analysis require a little further explanation. The analysis according to external input is the classic approach of the calorimetrist measuring energy flow in the whole animal in response to changes, e.g. in food intake or ambient temperature. Measurements of this sort are very numerous and while they may not be very profound in a metabolic sense, they are usually very precise and the limited conclusions that can be drawn from them can usually be drawn with confidence. Analysis according to internal input refers to the 'lower level' of the modeller who uses his knowledge of stoichiometry and the power of his computer to derive a more elegant and comprehensive picture of the flow of energy through an animal and the likely consequence to the animal of any perturbation of the inputs to the system. The disadvantage of this approach is that, at present, the uncertainty attached to some of the estimates can be large.

The philosophy behind the approach to analysis by internal output is that the metabolism of the animal is not so much driven by the amount of energy flowing into the system but pulled along by the requirement of different organs and tissues for energy substrates to regenerate (principally) ATP from ADP produced as a direct consequence of the work done by those tissues in support of maintenance, and, for example, growth or lactation. This form of analysis can be further subdivided into analysis by form or function. Analysis by form involves the measurement or estimation of $\mathrm{H}$ in different organs (e.g. the gut and liver). Analysis by function involves measurement of the contribution to total metabolic rate of energetically expensive processes such as protein synthesis. 


\section{Analysis by external input}

This topic is covered at length in most textbooks and reviews of energy metabolism. The schools of animal nutritionists which descended from Kellner have based their analysis of the utilization of feed energy by livestock on the very simple precept that for an animal at rest in a thermoneutral environment $\mathrm{H}$ is a function of the size of an animal (itself a function of body-weight, $\mathrm{W}$ ) and the amount of feed it eats (ME).

$$
\mathrm{H}=f_{1} \mathrm{~W}+f_{2} \mathrm{ME}
$$

This review will not consider behaviour, activity or thermoregulation but deal only with these effects of size and food intake and the extent to which they may be confounded by differences between animals in physiological state.

Size. Basal metabolism (F) is simply $\mathrm{H}$ when ME is zero and is therefore a mathematically precise way of relating $\mathrm{H}$ to $\mathrm{W}$. The interspecies relationship between F and W was explored by Brody (1945) and Kleiber (1961) who concluded that in adults $\mathrm{F}$ was $300 \mathrm{~kJ}(70 \mathrm{kcal})$ per $\mathrm{kg}$ body-weight ${ }^{0.75}$. The effect of increasing $\mathrm{W}$ on $\mathrm{F}$ in growing cattle (ARC, I980a) and pigs (ARC, 1980b) appears to be described better by $W^{0.67}$ which suggests that in these circumstances $F$ is closely related to surface area as originally propounded by Sarrus \& Rameaux in 1839 .

ME requirement for maintenance $\left(E_{m}\right)$ is obviously primarily determined by size though it is affected to a small degree by the quality of food eaten and its mode of digestion. For simple-stomached species $E_{m} \bumpeq I \cdot 3 F$, for ruminants it can vary between $\mathrm{I} \cdot 35$ to $\mathrm{I} \cdot 5 \mathrm{~F}$.

Simple rules exist therefore for predicting the effect of size on $\mathrm{H}$ for any animal. The question now arises, 'to what extent do different animals depart from these basic rules and why?' Blaxter ( 1967 ) reported that $F$ in sheep was below the interspecies mean; in cattle it was above. He also showed that $F$ was not a constant function of $\mathrm{W}$ in any individual but varied according to the previous physiological state of the animal. Webster (1978) has shown that the experimental processes involved in determining $F$ in the growing ruminant, which involve 4 weeks restriction of food intake followed by $4 \mathrm{~d}$ starvation, distort the relationship between size and $\mathrm{H}$ observed in the continuously growing animal. Therefore whether $\mathrm{F}$ is determined directly or predicted from measurements made on the animal in its normal physiological state, it cannot simply be considered a function of size (Webster et al. 1974), it also reflects the physiological state of the animal. The same applies to estimates of the so-called maintenance requirement of the growing or lactating animal. In the adult, of course, maintenance requirement is a real concept.

Table I compares measurements made of $\mathrm{E}_{\mathrm{m}}$ for sheep (Toutain et al. 1977), cattle (Webster et al. 1977), Zucker rats (Pullar \& Webster, 1977) and young adult kestrels (Kirkwood, 1981). These are not selected results; they are all the data I have which combine calorimetric measurements with measurements or estimates of body composition sufficiently precise to enable $\mathrm{H}$ to be related to lean body 
Table 1 . The maintenance requirement of different animals for metabolizable energy (ME) expressed /kg body-weight ${ }^{0.75}$ and / $/$ body protein $^{0.75}$

Interspecies mean ${ }^{\bullet}$

Sheept: yearling 'old', fat 'old', thin

Steers $ł$ : yearling, Friesian Hereford $\times$ Friesian

Zucker ratsil : lean fatty

Kestrel§ (Falco tinnunculus)

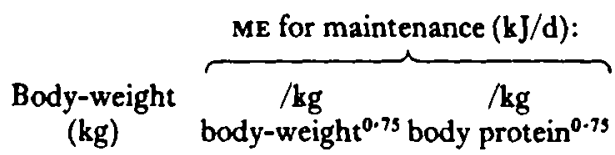

- 420 -

$56 \quad 385$

$73260 \quad 1295$

$58 \quad 310 \quad 1290$

$375 \quad 585 \quad 2305$

$375 \quad 500 \quad 2145$

$\begin{array}{lll}0.35 & 425 & 1550\end{array}$

$0.35 \quad 275 \quad 1550$

$\begin{array}{lll}0.24 & 610 & 1750\end{array}$

-Kleiber (196r).

†Toutain et al. (1977).

$\ddagger W$ ebster et al. (1977).

IIPullar \& Webster (1977).

§Kirkwood (Ig8I).

mass, or body protein content. Column 2 in Table $I$ relates $E_{m}$ to $W^{0.75}$. Sheep are consistently below the interspecies mean of $400 \mathrm{~kJ} / \mathrm{kg} \mathrm{W} \mathrm{W}^{0.75}$. Thus expressed, $\mathrm{E}_{\mathrm{m}}$ is lower in 'old' ( $4-6$ years) sheep than young sheep and $16 \%$ lower in fat animals than in thin ones. Cattle are above the interspecies mean and dairy-type (Friesian) animals have an $E_{m} 17 \%$ higher than beef-type (Hereford $\times$ Friesian) animals. Lean Zucker rats approximate to the interspecies mean but in fatty rats $\mathrm{E}_{\mathrm{m}}$ is $35 \%$ lower. The kestrel (Falco tinnunculus), which is an altricial (nest-fed) carnivorous bird has an $E_{m} 45 \%$ above the interspecies mean.

It is reasonable to attribute these differences in the first instance to differences in body composition rather than to any subtle changes in the metabolism of any particular tissue. For example, sheep may have a relatively low $\mathrm{E}_{\mathrm{m}}$ because they contain relatively large amounts of relatively inactive tissues like gut contents, fat and wool. The most metabolically active tissues are, in general, those which contain protein. Column 3 of Table $I$ expresses $E_{m}$ as a function of body protein ${ }^{0.75}$. The difference between fat and thin individuals now disappears for both rats and sheep which suggests ( 1$)$ that $E_{m}$ is better expressed as a function of lean mass than of $W$, and (2) that fat metabolism (excluding brown adipose tissue, BAT) contributes little to $H$. The very lean kestrel also approximates much more closely to the rat and therefore presumably to the interspecies mean. Differences between classes of cattle and between ages of sheep remain. These differences in metabolic rates of the same mass of tissue can tentatively (at this stage) be attributed to differences in fractional rates of synthesis and turnover of the major body constituents.

Food intake. It is necessary to begin this section by stating some very old truths. Increments of ME cannot either be stored in the body nor substitute for body 
tissues in energy metabolism at an efficiency of $100 \%$. In other words, the more ME an animal eats the more heat it produces. The ruminant, or Kellner, school of nutritionists calls this the heat increment of feeding (HIF) and has for years measured heat increments produced over periods of $24 \mathrm{~h}$ or longer by feeds of different quality in order to determine their net energy content. The monogastric or Rubner school called the same thing Specific Dynamic Effect (SDE), and, basing observations mostly on short-term measurements of $\mathrm{H}$ concluded, incorrectly, that for many simple feeds $\mathrm{H}$ was not elevated significantly by feeding. HIF and SDE are only operational definitions relating $\triangle H$ to $\triangle M E$ and are therefore the same thing, differing only in degree according to circumstances. The physiological explanation why $H$ increases with increasing $M E$ is complex and most attempts to explain HIF or SDE in physiological terms are incomplete (see Webster, I980).

Within the Rubner school there has been a revival of interest in the effect of food intake on H, which is now called 'Diet induced thermogenesis' (DIT). The Kellner team welcomed this latter-day awareness of HIF but were surprised to be informed by Rothwell \& Stock (I979) that Blaxter (1973) suggested that DIT (or HIF) was relatively unimportant in the regulation of energy balance. Blaxter and his colleagues have devoted more calorimeter time over the last 30 years to the measurement of HIF than to any other single topic. It is true to say, however, that most of this work has been concerned with differences between feeds in HIF rather than with differences in HIF between animals given the same feed.

The results of some thousands of energy balance studies with sheep have been analysed by Blaxter \& Boyne (1978) who show clearly the exponential decline in efficiency with which successive increments of $M E$ are used to promote energy retention, i.e. the exponential increase in HIF with increasing ME. Table 2 presents values for HIF for forage and cereal diets derived from the exponential equations

Table 2. Some estimates of the heat increment of feeding $(\mathcal{J} / \mathrm{kf} M E)$ above maintenance $\left(E_{m}\right)$

Ruminants* (UK): cereal $q 0.7$ forage $q 0.5$

Ruminants $\nmid$ (USA): cereal $q 0.7$

Zucker rats $\ddagger$ : lean forage $q 0.5$

fatty

Ratsll : cafeteria -control (from RE)

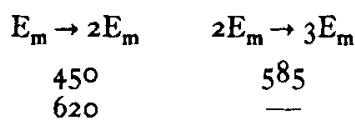

Above $\mathrm{E}_{\mathrm{m}}$

$54^{\circ}$

680

405

360

910

175

$q$, ME/gross energy.

- Blaxter \& Boyne (I978).

+National Academy of Science USA (1976).

†Pullar \& Webster (1977).

IIRothwell \& Stock (I979). 
of Blaxter \& Boyne (I978). For a cereal diet having a metabolizability $(q)$ of 0.7 , $\mathrm{HIF}$ is $45^{\circ} \mathrm{J} / \mathrm{kJ} \mathrm{ME}$ between maintenance and twice maintenance $\left(\mathrm{E}_{\mathrm{m}}\right.$ to $\left.2 \mathrm{E}_{\mathrm{m}}\right)$ rising to ${ }_{5}{ }_{5} \mathrm{~J} / \mathrm{kJ}$ ME between $2 \mathrm{E}_{\mathrm{m}}$ and ${ }_{3} \mathrm{E}_{\mathrm{m}}$. For a more fibrous forage diet HIF is 620 between $E_{m}$ and $2 E_{m}$ which is about as much as sheep would be able to consume. In these experiments HIF was determined from calorimetric experiments in adults retaining energy almost entirely as fat, and fed at different planes of nutrition at 4 -week intervals. The procedure used in the USA to derive values for net energy of feeds has been to feed different cattle or sheep continuously during growth at different planes of nutrition and compare $\mathrm{ME}$ and $\mathrm{RE}$ in the two groups. In these circumstances HIF is consistently higher than in changeover experiments with adults (Table 2) suggesting either that growth is less efficient than fattening or that a period of 4 weeks is not long enough fully to express differences in metabolism that can exist between ruminants getting different amounts of food.

Growth is undoubtedly less efficient than fattening in a strictly energetic sense. Pullar \& Webster (1977) summarizing calorimetric estimates, concluded that in simple stomached animals like the rat and the pig given highly digestible diets the apparent energetic efficiencies of protein and fat deposition were 0.44 and 0.74 respectively. The effect of this on HIF is seen in its most extreme form in animals differing in body composition as widely as lean and fatty Zucker rats and is in fact quite small, HIF for lean and fatty rats being 405 and $360 \mathrm{~J} / \mathrm{kJ}$ respectively (Table 2). Rothwell \& Stock (r979) measured energy balance in six rats fed ad lib. on a standard laboratory diet and six rats persuaded to overeat by being offered 'cafeteria' meals. The difference in total energy retention between control and 'cafeteria' groups over $2 \mathrm{I}$ d was very small, implying an HIF of $910 \mathrm{~J} / \mathrm{kJ} \mathrm{ME}$ (Table 2). However, the difference in resting $\mathrm{H}$ estimated from $\mathrm{O}_{2}$ consumption (assuming $20.4 \mathrm{~J} / \mathrm{ml} \mathrm{O}_{2}$ ) was also rather small, implying an $\mathrm{HIF}$ of only 175 . The extreme discrepancy between the calorimetric and comparative slaughter approaches to measuring energy balance needs to be resolved before it can be concluded with confidence that HIF in the cafeteria fed rats was substantially different from that observed by other workers in rats and other species.

Sites of thermogenesis. In order to analyse differences in $\mathrm{H}$ according to output it is necessary to measure, or estimate, $\mathrm{H}$ in different organs or the association between $\mathrm{H}$ and different metabolic functions. We have had a limited degree of success in measuring total and aerobic $\mathrm{H}$ in the portal-drained viscera of the sheep (Webster et al. 1975). Since our technique depends on implantation of catheters and transducers into the afferent and efferent blood vessels of an organ it requires that these vessels be large and that at least one of them be single. One can, however, obtain an approximate estimate of $\mathrm{H}$ in different organs simply by measuring blood flow since there are finite limits to the difference that can exist between the $\mathrm{O}_{2}$ contents of arterial and venous blood $\mathrm{C}(\mathrm{a}-\mathrm{v})$. Foster \& Frydman ( 1978 ) have made comprehensive measurements of blood flow to different organs of rats, using radioactive microspheres and augmented these measurements where possible by measurements of $\mathrm{C}(\mathrm{a}-\mathrm{v})$. Their observations on warm-acclimated rats 
Table 3. Distribution of blood flow and estimated $\mathrm{O}_{2}$ consumption, rats at rest, derived from Foster \& Frydman (1978)

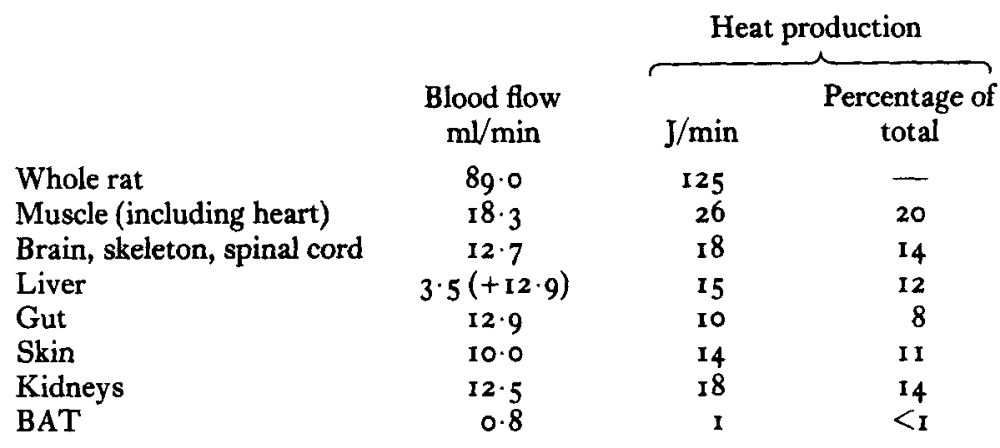

at rest are shown in Table 3. Again, assuming $20.4 \mathrm{~J} / \mathrm{ml} \mathrm{O}_{2}$, one can calculate the contribution made by various organs to total $\mathrm{H}$. In this example muscle contributes $20 \%$ and liver and gut a further $20 \%$. The values for gut are particularly susceptible to uncertainties as to $\mathrm{C}(\mathrm{a}-\mathrm{v})$. Here it is assumed (by me) to be only $3.8 \mathrm{ml} \mathrm{O}_{2} / 100 \mathrm{ml}$ blood as against 6.9 for the body in general. Foster \& Frydman (1978) proceed to demonstrate clearly that, following acclimation to cold, the increase that occurs in blood flow to brown adipose tissue (BAT) is sufficiently large to implicate BAT as the primary, if not the only, site of non-shivering thermogenesis in this species. The microsphere technique is undoubtedly a powerful aid to the analysis on an organ by organ basis of differences in $\mathrm{H}$ arising for other nutritional or genetic reasons. However, in farm animal species, at least, there is no evidence to suggest a significant role for BAT except in the neonate.

Hales (1974) has measured regional blood flow in sheep using the same approach. Table 4 presents a less discrete breakdown of the fractional distribution of blood flow into that through abdominal organs ( $48 \%$, including kidneys), muscle $(\mathrm{x} 5 \%)$, skin (x $1 \%$ ) and other tissues $(26 \%)$. Webster ( 1980$)$ concluded from direct measurements that the gut and liver of sheep contribute about $40 \%$ to total $\mathrm{H}$ of a

Table 4. Fractional distribution of blood flow, protein synthesis and heat production in ruminants

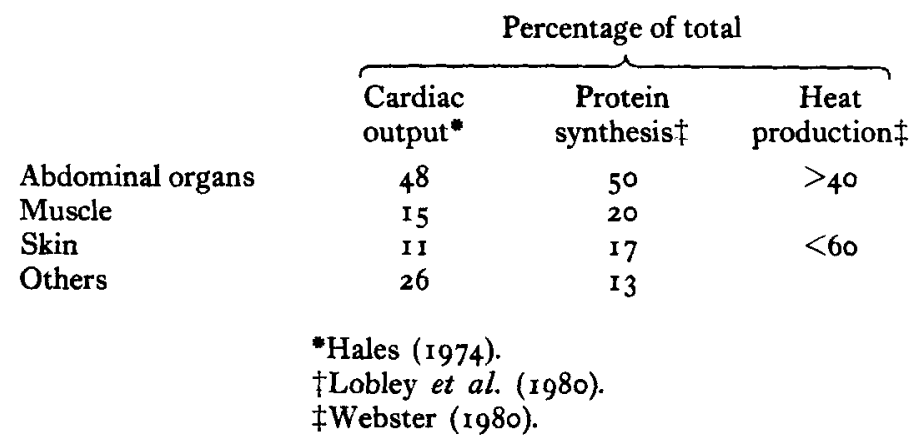


sheep at rest and also drew attention to the close association between rates of $\mathrm{H}$ and rates of protein synthesis, both on a between animal basis and a between tissue basis. On a between species basis the relationship appears to be $20 \mathrm{~kJ} \mathrm{H} / \mathrm{g}$ protein synthesized. The direct energy cost of protein synthesis is estimated at about $4.5^{-5} \mathrm{~kJ} / \mathrm{g}$, which suggests that these may be responsible for about $20-25 \%$ of $\mathrm{H}$ in the animal at rest. The very close statistical association between $\mathrm{H}$ and protein synthesis does, however, suggest that, for whatever precise reason, protein synthesis is a good predictor of $\mathrm{H}$ and vice versa. Table 4 also presents values for fractional rates of protein synthesis in tissues of cattle (based on incorporation of $\left[{ }^{3} \mathrm{H}\right]$ tyrosine from tissue homogenate (Lobley et al. 1980 ). There is a close similarity between these estimates and those of blood flow obtained by Hales (1974) (Table 4), which suggests that these values constitute a good first approximation to $\mathrm{H}$ in these different organs. The estimates of $\mathrm{H}$ for muscle and skin are quite similar for rats and sheep. Both sets of observations point to the fact that muscle, despite its mass, makes a relatively small contribution to $\mathrm{H}$. Liver, gut and kidneys contribute $43 \%$ to $\mathrm{H}$ in the rat, total abdominal organs contribute about $50 \%$ in the sheep. Again, considering differences between species in mass of gut tissue and mode of digestion, these values are reassuringly similar.

These values do not yet reveal reasons why $H$ should differ between animals. Rothwell \& Stock (1979) and Foster \& Frydman (1978) are amongst the many who have explored the particular role of BAT in $\mathrm{H}$ of the rat. Webster ( 1980 ) explored the contribution of the portal-drained viscera and other tissues to HIF in sheep, in each case using techniques reviewed here. These are only beginnings. This review does not pretend to offer any complete answers as to why animals may differ in $\mathrm{H}$ and thus in the energetic efficiency of metabolism. It does, however, present techniques which are available for this form of analysis. It suggests, moreover, that whereas estimates of protein synthesis from incorporation of labelled amino acids or estimates of blood flow using labelled microspheres may have a considerable element of uncertainty in themselves, there are fundamental biological reasons why both should be reasonably closely related to $H$. Therefore, when both independent approaches lead to approximately the same estimates of $\mathrm{H}$ there is good reason to suppose that they are about right.

\section{REFERENCES}

Agricultural Research Council (1980a). The Nutrient Requirements of Farm Livestock No. 2. Ruminants, and ed. London: Agricultural Research Council.

Agricultural Research Council (1980b). The Nutrient Requirements of Farm Livestock No. 3. Pigs, and ed. London: Agricultural Research Council.

Blaxter, K. L. (I967). The Energy Metabolism of Ruminants, and ed. London: Hutchinson.

Blaxter, K. L. (1973). Obesity in Perspective, [G. A. Bray, editor]. pp. 1 27-136. DHEW Pub. No. (NIH) 75-708.

Blaxter, K. L. \& Boyne, A. W. (1978). F. agric. Sci., Camb. 90, 47.

Brody, S. (1945). Bioenergetics and Growth. New York: Reinhold.

Foster, D. O. \& Frydman, M. Lorraine (1978). Can. F. Physiol. Pharmacol. 56, I Io.

Hales, J. R. S. (1974). MTP int. Rev. Sci. Environ. Physiol. p. 107. [D. Robertshaw, editor]. London: Butterworths. 
Kirkwood, J. K. (1981). Proc. Nutr. Soc. 40,6A.

Kleiber, M. (196r). The Fire of Life. New York: Wiley.

Lobley, G. E., Milne, V., Lovie, J. M., Reeds, P. J. \& Pennie, K. (Ig80). Br. F. Nutr. 43, 49I.

National Academy of Sciences (1976). Nutrient Requirements of Beef Cattle $5^{\text {th }}$ ed. Washington DC: National Academy of Sciences.

Pullar, J. D. \& Webster, A. J. F. (1977). Br. F. Nutr. 37, 355.

Rothwell, N. J. \& Stock, M. J. (1979). Nature, Lond. 281, 31 .

Toutain, P. L., Toutain, Claire, Webster, A. J. F. \& McDonald, J. D. (1977). Br. F. Nutr. 38, 445.

Webster, A. J. F. (1978). Wld Rev. Nutr. Dietet. 30, 189.

Webster, A. J. F. ( $\mathrm{rg} 80$ ). Digestive Physiology and Metabolism in Ruminants [Y. Ruckebusch and P. Thivend, editors]. p. 423. Lancaster: MTP Press.

Webster, A. J. F., Brockway, J. M. \& Smith, J. S. (1974). Anim. Prod. 19, 127.

Webster, A. J. F., Osuji, P. O., White, F. \& Ingram, J. F. (1975). Br. F. Nutr. 34, 225.

Webster, A. J. F., Smith, J. S. \& Mollison, G. S. (r977). Anim. Prod. 24, 237. 